Culturas populares e identificações emergentes: Reflexões a partir do manguebeat e de expressões musicais brasileiras contemporâneas

Popular Cultures and Emerging Identifications: Reflections from Manguebeat and Contemporary Brazilian Musical Expression

Cultures populaires et identifications émergentes: réflexions à partir de manguebeat et des expressions musicales brésiliennes contemporaines

Luciana F. M. Mendonça

C OpenEdition

Journals

Edição electrónica

URL: http://journals.openedition.org/rccs/622

DOI: $10.4000 /$ rccs.622

ISSN: 2182-7435

Editora

Centro de Estudos Sociais da Universidade de Coimbra

Edição impressa

Data de publição: 1 Setembro 2008

Paginação: 85-109

ISSN: 0254-1106

Refêrencia eletrónica

Luciana F. M. Mendonça, « Culturas populares e identificações emergentes: Reflexões a partir do manguebeat e de expressões musicais brasileiras contemporâneas », Revista Crítica de Ciências Sociais [Online], 82 | 2008, colocado online no dia 01 outubro 2012, criado a 03 maio 2019. URL : http:// journals.openedition.org/rccs/622; DOI : 10.4000/rccs.622 


\title{
Culturas populares e identificações emergentes: Reflexões a partir do manguebeat e de expressões musicais brasileiras contemporâneas'
}

\begin{abstract}
O artigo analisa a interacção de diversos factores que, relacionados com transformações socioculturais recentes, contribuem para a centralidade da música e de outras formas de expressão estética em processos de rearticulação das identidades, no âmbito dos quais se observa um renovado interesse pelas manifestações populares tradicionais e a dinamização de espaços urbanos. Buscando a comparação com outros contextos, toma-se como ponto de partida o estudo do movimento manguebeat, de Recife, Pernambuco, cujos elementos permitem a discussão de questões ligadas às relações entre - local e o global, a tradição e a modernidade, a criação e a fruição cultural. A pesquisa confirmou algumas tendências da música contemporânea, que colocam certas formas musicais regionais em sintonia com as transformações do campo musical em geral. Uma questão chave é a dos processos de ressignificação das culturas populares.
\end{abstract}

\section{Introdução}

Várias razões têm sido levantadas, no amplo escopo de pesquisas sobre a cultura contemporânea, para definir a música, ${ }^{2}$ vista na totalidade dos seus processos de produção, circulação e consumo, como tema frutífero de investigação empírica: 1) o seu forte apelo como elemento de comunicação entre e dentro de grupos; 2) o facto de estar frequentemente envolvida com mecanismos de identificação social, de redefinição e criação de novas identidades e estilos de vida, em especial juvenis (Connor, 1992; Featherstone, 1995); 3) a sua natureza de produto lucrativo e extremamente relevante para a indústria cultural (a despeito de/ e considerando as novas formas de fruição e consumo que se consolidaram com as tecnologias digitais); 4) ser parte constitutiva dos cenários e paisagens sociais, estando presente em todos os

\footnotetext{
${ }^{1}$ Uma versão preliminar deste artigo foi publicada nas Oficinas CES n. ${ }^{\circ} 275$, disponível em http:// www.ces.uc.pt/publicacoes/oficina/275/275.php.

${ }^{2}$ Sobre a sua importância geral, pode-se dizer que "Música é manifestação de crenças, de identidades, é universal quanto à sua existência e importância em qualquer que seja a sociedade" (Pinto, 2001: 223).
} 
ambientes, sobretudo no meio urbano, onde se podem analisar as sonoridades que marcam a especificidade de um dado local (cf. Fortuna, 1999 e 2001: 5) tratar-se de um dos campos de expressão dos hibridismos, ${ }^{3}$ que têm sido pensados como característicos dos processos de criação cultural nas sociedades contemporâneas. A emergência do rótulo world music ${ }^{4}$ e de um mercado musical específico a ele associado, a partir dos anos 1980, é uma das expressões deste fenómeno.

Uma das manifestações musicais brasileiras mais significativa em termos do seu forte envolvimento com processos de reelaboração das identificações sociais e encenação de uma produção cultural marcada pelo hibridismo, nos anos 1990, foi o movimento manguebeat, cooperativa cultural cujo marco de criação estabeleceu-se com a publicação na imprensa do Recife, em 1991, de um manifesto intitulado "Caranguejos com cérebro". ${ }^{5} \mathrm{O}$ movimento teve como principais expoentes os músicos/bandas Chico Science \& Nação Zumbi, Fred Zero Quatro e Mundo Livre S/A. ${ }^{6}$ A importância do manguebeat na dinamização do contexto local prende-se ao facto de ter potencializado as possibilidades de expressão de diversos artistas e grupos musicais ao valer-se do mangue ${ }^{7}$ como metáfora da diversidade cultural local, contribuindo para ressignificar as mais variadas manifestações da

\footnotetext{
${ }^{3}$ Utiliza-se aqui hibridismo/hibridação, como faz Canclini (1997), por possibilitar o tratamento de diversos tipos de mesclas interculturais, evitando a carga racial do termo "mestiçagem" e a religiosa e tradicional, associada ao termo "sincretismo". Outra abordagem interessante do tema encontra-se em Burke (2003).

${ }^{4}$ Van der Lee (1998) elaborou uma interessante tipologia do campo semântico recoberto pela expressão, com definições correlacionadas e ordenadas hierarquicamente, da forma considerada "mais autêntica" para a mais "misturada" ou "corrompida", segundo a avaliação do público médio ocidental, o que demonstra a variedade de formas que se pode encontrar subsumida a este rótulo. A tipologia cobre sete concepções de world music, que iriam desde a música tradicional não-ocidental (indígena, indiana, árabe, etc.) ou da música popular e nacional (neste caso, incluindo os países ocidentais), até as assimilações de géneros mundializados por países periféricos ou vice-versa, incluindo a descontextualização e justaposição de elementos sonoros de diversas origens.

${ }^{5}$ O manifesto foi redigido por Fred Zero Quatro - compositor e vocalista da Mundo Livre S/A - com a colaboração de Renato Lins - jornalista e DJ - e ilustrado por Helder Aragão, o DJ Dolores, que foi responsável, junto com seu parceiro Morales, pelo projecto gráfico e ilustrações do encarte do primeiro CD de Chico Science \& Nação Zumbi, Da lama ao caos, onde também foi publicado o manifesto (Teles, 2000).

${ }^{6}$ Referências a links para o acesso na Internet a videoclipes dessas bandas e também da Devotos, que será mencionada abaixo, podem ser encontrados no final do artigo. A lista, longe de ser extensiva, serve apenas como indicação básica para o leitor que queira conhecer um pouco do trabalho musical das bandas citadas ao longo deste artigo.

${ }^{7} \mathrm{O}$ mangue ou manguezal é um ecossistema com grande diversidade biológica, característico de regiões costeiras da América do Sul, Ásia e África, sobretudo nas regiões dos deltas dos rios, geralmente lamacentas e alagadas por água salobra. Nos mangues prolifera uma vegetação com raízes aéreas e muitas espécies de crustáceos, sobretudo caranguejos. Na Região Metropolitana do Recife há muitas áreas de mangue e significativas partes da cidade foram construídas sobre zonas de mangue aterradas.
} 
cultura popular regional e promovendo, nesse bojo, a valorização da cultura tradicional e dos seus produtores.

Além disso, o manguebeat faz parte do conjunto de modificações que têm impacto sobre a música popular brasileira e fazem com que o rótulo MPB ganhe novos sentidos, ao se relacionar com as formas contemporâneas de criação musical urbana, suscitando novas formas de hibridismo. A questão não é apenas de classificação e definição de géneros musicais, mas envolve o sentido da produção contemporânea, que não pode mais ser caracterizada a partir do território nacional como referência central:

MPB pode servir para Edu Lobo, Guinga, Caetano... E para Skank, Chico Science, Ed Mota, Cássia Eller, Titãs, Paralamas e Sepultura? Quais são as fronteiras que distinguem claramente uma coisa da outra? MPB serve e não serve para definir uma produção de música urbana vital, em processo de transformação, com muita absorção de diferentes sons e dotada de diferentes sotaques, que vão se modulando, se combinando e se contrapondo. (Wisnik, 1997: 58-60)

Considerando-se esse contexto de absorção e combinação de diferentes sons, pretende-se reflectir tanto sobre as condições colectivas que propiciaram a emergência do manguebeat no panorama musical, quanto sobre a sua constituição como objecto de reflexão, sua inserção e especificidade no contexto das paisagens sonoras locais e globais. Discutem-se ainda algumas das consequências sobre a rearticulação das identidades culturais e o reposicionamento das culturas populares no interior da sociedade contemporânea.

\section{Manguebeat: um objecto "bom para pensar"}

Em 1998, quando se iniciou a pesquisa sobre esse tema ${ }^{8}$, praticamente não existia bibliografia que tomasse o movimento manguebeat como assunto. Em 2004, já havia diversos artigos publicados em livros e revistas especializadas, comunicações em congressos, mais de uma dezena de dissertações de mestrado e teses de doutoramento, além de inúmeros artigos em jornais e revistas genéricas ou dedicadas exclusivamente à música, tanto no Brasil como no exterior (sobretudo nos Estados Unidos da América), abrangendo as áreas das ciências sociais, comunicação, (etno)musicologia, história e crítica da música popular. Seria o caso de nos perguntarmos: porquê um fenómeno tão recente, com pouco mais de dez anos, de cariz local (embora relacionado a circuitos transnacionais), com forte relação com as tradições populares, mas caracterizado por ser uma forma de produção cultural “alter-

\footnotetext{
${ }^{8}$ Esta investigação foi desenvolvida no âmbito do meu doutoramento (Mendonça, 2004).
} 
nativa" (à margem do mercado mainstream), consumida principalmente por alguns segmentos do público jovem, atraiu para si a atenção não só dos media, mas também dos intelectuais?

Embora a atenção às práticas culturais populares em geral - analisadas agora com o mesmo grau de sofisticação teórica antes aplicado à cultura erudita - faça parte das tendências contemporâneas (Connor, 1992), a história do manguebeat e dos eventos que lhe deram forma ajuda-nos a compreender os motivos que levaram este movimento cultural a se tornar um objecto considerado "bom para pensar", sem minimizar os aspectos estéticos, postos em relevo por certos investigadores, sobretudo por se terem constituído como elementos de atracção inicial que os impulsionou a debruçarem-se sobre o assunto. ${ }^{9}$

Entre os factores que me atraíram para o tema, para além das questões teóricas discutidas a seguir, a audição do CD Da lama ao caos, ${ }^{10}$ de Chico Science \& Nação Zumbi, e o contacto com as notícias que circulavam nos meios de comunicação sobre o desenvolvimento do manguebeat, desde o início dos anos 1990, no Recife, vieram consolidar o interesse por um estudo de caso específico. Esse caso parecia ter (e de facto tem) inúmeros elementos interessantes para a reflexão, sobretudo quanto aos desdobramentos das relações entre o local e o global no campo da identidade cultural, em imbricação com os processos de criação musical.

$\mathrm{Na}$ pesquisa realizada, os dados etnográficos ${ }^{11}$ foram complementados com pesquisa documental em jornais, revistas e sites da Internet. Foi fundamental para o desenvolvimento do trabalho colocar em confronto com os dados empíricos a hipótese segundo a qual existe uma relação dialéctica entre, por um lado, as forças ao mesmo tempo homogeneizantes e segmentadoras da mundialização da cultura e, por outro, a heterogeneidade de fontes e

\footnotetext{
${ }_{9}$ O etnomusicólogo Philip Galinsky (2002) relata que ficou muito impressionado quando viu o show da Nação Zumbi, em 1995, no Summerstage, Central Park, Nova Iorque, sobretudo com a performance de Chico Science e com o som propriamente dito, que foram, segundo o autor, o ponto de partida para a decisão de investigar o manguebeat.

${ }^{10}$ Quanto ao impacto de Da lama ao caos, pesquisadores e críticos musicais apontam o disco como grande inovação no conjunto da MPB da última década. Um indício desse facto foi a sua eleição, em 2004, como um dos "dez grandes álbuns da história da música brasileira", em votação organizada pelo Sesc Pompeia, um dos aparatos culturais mais importantes da cidade de São Paulo, gerido pelo Serviço Social do Comércio (Folha de São Paulo, 2005).

${ }^{11}$ A investigação de terreno no Recife foi feita de maneira mais sistemática em dois períodos de cerca de um mês, em Janeiro/Fevereiro de 1999 e de 2001, períodos durante os quais se desenvolveu a observação de concertos e do Carnaval, quando acontece um dos festivais mais importantes da cena mangue, o Recbeat. Nesses períodos, realizaram-se também entrevistas e recolheram-se depoimentos de actores-chave naquele cenário (músicos, produtores, jornalistas). Realizaram-se outras observações de concertos, como a do festival Abril Pro Rock, em 2000, de dois concertos no exterior (em Berlim e em Lisboa), além de outros realizados em São Paulo.
} 
resultados da produção cultural local, tanto em termos de conteúdos, como das relações de poder. Neste sentido, a busca de um estudo de caso teve também motivações de natureza teórica, que remetem para os debates sobre os processos de globalização e de mundialização da cultura, onde se encontravam algumas lacunas, apontadas também por autores como Crane (2002), quanto à comprovação empírica de alguns postulados tidos como universais.

Retomando os motivos que tornaram o manguebeat "bom para pensar", algumas características próprias do movimento devem ser relembradas.

Em primeiro lugar, o movimento mangue surgiu, em grande parte, como reacção a um cenário de estagnação económica e cultural, na "ressaca" dos anos 1980 - no Brasil, a chamada "década perdida", em função da crise económica que se instalou. Era um contexto de poucas oportunidades de lazer e de trabalho para os jovens, problemas que apresentam uma face ainda mais perversa numa metrópole periférica como o Recife. ${ }^{12}$ Enquanto reacção espontânea, baseada no ideário punk do "faça você mesmo", o que era um grupo informal de amigos acabou por se transformar na cooperativa cultural mangue. Ou, dito de outro modo, por meio das acções de ajuda mútua, da dinamização dos espaços de lazer e da criação cultural na cidade, valorizando os elementos locais, criou-se um conjunto de eventos e produtos - festas, festivais, discos, filmes, exposições, etc. - apreendidos pelo público e pelos media como um movimento cultural. Esse aspecto informal dá ao movimento um potencial de atrair para a sua esfera de influência outros grupos que circulam ao seu redor, compartilhando com eles a sua capacidade de projecção pública.

Quanto a este primeiro ponto, um dos exemplos mais interessantes de bandas associadas ao manguebeat, mas que não se consideram propriamente parte do movimento, nem se utilizam do mesmo manancial de ideias e mesclas musicais que a Nação Zumbi e a Mundo Livre S/A, é o das bandas do Alto Zé do Pinho, bairro pobre, deficitário no que diz respeito à infraestrutura e aos serviços públicos, localizado num dos morros da zona Norte do Recife. Na visão de alguns músicos e críticos musicais, este bairro constituiria mesmo uma cena ${ }^{13}$ musical à parte, que se caracterizaria pela predominância do hardcore. Bastante representativos desse contexto são os Devotos (antes, Devotos do Ódio), banda criada em 1988, mas que só teve

\footnotetext{
${ }_{12}$ A Região Metropolitana do Recife é a $9^{a}$ maior do Brasil e a maior da região Nordeste, com 3,3 milhões de habitantes. Dela fazem parte 14 municípios, sendo Recife, com cerca de 1,5 milhões de habitantes, a cidade sede da Região Metropolitana (IBGE, Censo 2000).

13 A metáfora da cena tem origem no movimento punk inglês e qualifica um fazer cultural que trabalha com circuitos de produção e consumo interligados, mas não uniformizados em termos estéticos.
} 
o seu primeiro disco lançado em 1996, na esteira da projecção das principais bandas do mangue. Como esta, outras bandas do Alto Zé do Pinho passaram a ter maiores oportunidades, tendo-se implementado um projecto com finalidades educativas, económicas e de solidariedade social, denominado Alto Falante (cf. Mendonça, 2004, especialmente Capítulo 6). Além disso, a própria imagem do bairro foi valorizada, deixando, por exemplo, de ser assunto das páginas policiais dos jornais, para figurar nas secções de cultura.

Em segundo lugar, é importante ressaltar o carácter social transfronteiriço do movimento, ao colocar em diálogo pessoas de classes sociais, origem geográfica (dentro do espaço urbano), estilos de vida e perspectivas diferentes. O núcleo inicial do manguebeat apoiava-se em duas pedras angulares: o grupo de amigos de Peixinhos/Rio Doce (Olinda), que se aglutinava ao redor de Chico Science, e o grupo da praia de Candeias, cujo pedaço ${ }^{14}$ foi baptizado de "Ilha Grande", tendo como personalidades centrais o músico Fred Zero Quatro e o jornalista Renato Lins. Os dois grupos funcionavam como circuitos de troca de informação e como espaço aglutinador de músicos, compositores, bandas e gente ligada à criação cultural, com pontos de contacto entre eles. É interessante notar que os bairros - Peixinhos/Rio Doce, em Olinda, e, do outro lado, Candeias, em Jaboatão dos Guararapes - situam-se em pontos distanciados, opostos, respectivamente, a norte e a sul da Área Metropolitana do Recife. Também do ponto de vista social, o primeiro grupo caracteriza-se por ser de classe baixa ou média-baixa, e o segundo de classe média ou média-alta. Enquanto o segundo grupo era mais nitidamente adepto do rock, o primeiro estava mais claramente ligado à chamada música negra, sobretudo ao funk e ao rap.

Do ponto de vista do público, essa característica aparece mais uma vez, pois o mangue conta com fãs tanto no conjunto dos universitários de classe média e alta, quanto entre os jovens de classe baixa, alguns moradores de favelas. ${ }^{15}$ Muito contribuiu para esse carácter transclassista a figura de Chico Science, músico de maior projecção do movimento, criador do rótulo manguebeat. Sua capacidade de aglutinar pessoas e sons, sua personalidade expansiva e carismática, sua capacidade criativa e performática, mobilizando símbolos extremamente enraizados na cultura pernambucana, transforma-

\footnotetext{
${ }^{14}$ Utilizo aqui a noção de pedaço elaborada por José Guilherme Magnani a partir da etnografia urbana e exposta em vários textos do autor. De acordo com ele: "A noção de pedaço [...] supõe uma referência espacial, a presença regular dos seus membros e um código de reconhecimento e comunicação entre eles" (Magnani, 2002: 20).

15 Ao ressaltar o carácter transclassista do movimento, tanto do ponto de vista da produção quanto do consumo culturais, não se pretende afirmar que as fronteiras de classe social tenham sido rompidas. Verifica-se apenas que existem certas porosidades que permitem novos arranjos e relações com os conteúdos culturais e com o espaço urbano.
} 
ram-no num ídolo da juventude, especialmente a local. A sua morte prematura, em Fevereiro de 1997, ajudou a projectá-lo ainda mais. Nas palavras de um crítico musical do Recife:

Enquanto bandas de rock e outros artistas do resto do país falavam de temas mais comuns a uma juventude burguesa, ele falava em urubu, molambo, lama, palavreado que nunca esteve em primeiro plano na música pop. Ele abordava originalmente temas do quotidiano de uma juventude que necessitava expressar-se e não tinha os meios para tal. Essa combinação de necessidade e oferta, conjugada com sua morte, teria desembocado na sua mitificação. (Santiago, 2001)

Em terceiro lugar, o carácter transfronteiriço acima referido expressa-se também no plano estético, com a conjugação de tradições e inovações díspares, num processo de recriação musical e visual a partir de fontes diversas. No plano visual, misturam-se tendências relacionadas à cultura piscatória do litoral nordestino e/ou à cultura sertaneja com o $p \circ p$ mundializado, buscando uma forma de manifestação estética própria, tanto na performance, quanto no videoclipe, na moda, na fotografia e no cinema. ${ }^{16}$ No plano sonoro, a interacção é vívida e intensa, sobretudo quando consideramos a profundidade histórica e a presença quotidiana simultânea, em disputa ou em convívio harmonioso, das tradições pernambucanas/nordestinas e da música pop mundializada (do rock em suas mais variadas vertentes, da música popular negra, especialmente do funk e do rap), ambas traduzindo, cada qual a seu modo, as condições de vida da juventude nas periferias do capitalismo. No entanto, ao combinar essas duas vertentes em criações híbridas, o manguebeat produziu formas musicais capazes de seduzir um público mais amplo do que aquele constituído pelos defensores e "detentores" da cultura tradicional, contribuindo para a maior aceitação das sonoridades locais/regionais - antes, desvalorizadas e residuais ${ }^{17}$ - ao combiná-las com sonoridades pertencentes à cultura jovem mundializada.

\footnotetext{
${ }_{16}$ O baile perfumado, Amarelo manga, $O$ rap do pequeno príncipe contra as almas sebosas e, mais recentemente, Árido movie e Baixio das bestas são produções cinematográficas sintonizadas com essa busca. Para os directores de O baile perfumado, Lírio Ferreira e Paulo Caldas, "a mistura inquieta de estilos, linguagens e ritmos é o paralelo comum que existe entre a música (mangue bit) e o cinema (árido movie) que se faz no Recife" (Encarte do CD da Trilha Sonora do filme O baile perfumado. Natasha Records, 1997).

${ }_{17}$ Utiliza-se, aqui, a noção de residual no mesmo sentido em que a define Raymond Williams (1979: 125): "Por 'residual' quero dizer alguma coisa diferente do 'arcaico' [...] chamaria de 'arcaico' aquilo que é totalmente reconhecido como um elemento do passado, a ser observado, examinado, ou mesmo, ocasionalmente, a ser 'revivido' de maneira consciente, de uma forma deliberadamente especializante. [...] O residual, por definição, foi efetivamente formado no passado, mas ainda está ativo no processo cultural [...]. Assim, certas experiências, significados e valores que não se podem
} 
Pode-se dizer que, ao utilizar as paisagens sonoras mundializadas do pop/rock e da música negra norte-americana sem, no entanto, se fechar em torno de um projecto estético ortodoxo, o mangue tornou possível a aglutinação de bandas com várias tendências. Além disso, tornou as sonoridades tradicionais mais facilmente audíveis para um conjunto alargado de segmentos sociais, nomeadamente: a) cidadãos do Recife, sobretudo os jovens de estratos populares, que têm uma memória da música local; b) parcelas do público urbano em busca de novidades, nacionalmente, dentro do campo da MPB e, internacionalmente, no campo da world music; c) músicos em busca de renovação de seus processos criativos e/ou de expressão de suas identidades específicas (geracionais, étnicas, nacionais, regionais, locais etc.).

Além da valorização geral da produção cultural local, ao projectar toda a cena recifense no âmbito nacional e em certos circuitos da cultura mundializada, o manguebeat fez com que os artistas e outros segmentos sociais do Recife, em especial os jovens de todas as classes sociais, voltassem mais o olhar para as tradições regionais, processo que está em sintonia com a onda de revalorização das culturas populares tradicionais, como se discutirá abaixo. Este facto contribuiu para reforçar a auto-estima e as identidades sociais vinculadas a essas "heranças" culturais antes residuais. A própria diversidade dessa "herança" passou a estar em foco e a ser valorizada como equivalente à riqueza cultural.

Gilmar Bolla 8, percussionista da Nação Zumbi, afirmou que, embora os ritmos locais estejam na memória de muitos músicos, para um público mais amplo "maracatu, coco, ciranda, ${ }^{18}$ hoje é que é conhecido. Há dez anos ninguém falava" ${ }^{19}$. Esses ritmos só tinham uma presença mais significativa no

expressar, ou verificar substancialmente, em termos da cultura dominante, ainda são vividos e praticados à base do resíduo [...] de uma instituição ou formação social e cultural anterior." Pelo lugar que têm vindo a ocupar na vida quotidiana, muitas formas de expressão da cultura popular pernambucana podem ser apropriadamente qualificadas como tendo sido, em determinados momentos, residuais: vividas no cotidiano por certos segmentos sociais, mas invisibilizadas no quadro da cultura dominante.

${ }^{18}$ Os maracatus estão entre as mais importantes manifestações culturais de Pernambuco. Há dois tipos de maracatu. O primeiro, o maracatu de baque virado ou nação, é aparentemente, mais africanizado e tem suas raízes na congada, que representa a coroação do rei e da rainha Congos, tradição africana reinterpretada no Brasil. Documentos históricos atestam a existência do maracatu nação desde o início do século XIX. O segundo, o maracatu rural, de baque solto ou de orquestra vem da Zona da Mata pernambucana e exibe influências indígenas, tanto na música como nas personagens que se apresentam. O coco parece ter tido origem no Estado de Alagoas, mas se espalhou sobretudo pelas regiões Norte e Nordeste, incluindo-se na tradição de canções de trabalho. Há vários tipos de coco, classificados de acordo com os instrumentos utilizados, a região de origem, o tipo de verso, etc. A ciranda é uma dança de roda de origem portuguesa, com trovas cantadas, por vezes acompanhadas por instrumentos de percussão e/ou de cordas e sopro. Uma referência clássica sobre os diversos ritmos e folguedos brasileiros é Cascudo (1988).

${ }_{19}$ Depoimento concedido a esta autora em Fevereiro de 2001. 
Carnaval. A jornalista Michele D'Assumpção, pertencente à mesma geração que a maior parte dos músicos da cena, também expressou a importância da memória sobre as tradições locais: "Todo o mundo aqui em Pernambuco quando criança ouviu maracatu, frevo, caboclinhos. ${ }^{20}$ Essa galera assimilou isso aí. Essa música está na minha memória”. ${ }^{21} \mathrm{E}$, vale reiterar, nessa actualização da memória, os criadores e mantenedores das tradições foram revalorizados, por terem deixado de ser vistos como produtores de uma cultura "subalterna", e ganharam maior espaço de circulação pública.

Resumindo os três pontos levantados acerca do mangue como objecto "bom para pensar", destacam-se: 1) o carácter “espontâneo" de mobilização e de reacção a um contexto de estagnação social, cultural e económica; 2) o carácter transfronteiriço do ponto de vista sócio-geográfico no espaço urbano do Recife; 3 ) o carácter híbrido do ponto de vista estético (cruzando fronteiras entre o local e o global, a cultura popular e a indústria cultural). Essas características foram levadas em conta na construção do objecto de investigação, possibilitando empreender reflexões sobre as identidades, hegemonias e contra-hegemonias, que formaram, por assim dizer, o núcleo duro das questões abordadas ao longo do trabalho de pesquisa.

Pela atenção às dinâmicas sociais que podem levar a novas configurações sócio-culturais, foi fundamental ter em conta a reaç̧ão espontânea, as relações entre sujeitos de classes sociais e locais de moradia diversos, com gostos e estilos de vida variados, promovendo relações sociais e estéticas que transcendem fronteiras concretas e simbólicas, animando espaços centrais (então esvaziados) da cidade, num contexto também de transformações macroestruturais (no capitalismo global, na esfera do Estado, na indústria cultural). Mas o que me interessava primordialmente era o novo equilíbrio produzido por esses processos criativos, que sempre são reprodução. ${ }^{22}$ Visto que a reprodução nunca é apenas uma total reposição do mesmo, eles são portadores de mudanças, mesmo que pequenas, no equilíbrio de poder no campo cultural. Apesar da força do policiamento, da regulação e da cooptação em relação à transgressão na cultura popular, interesso-me, como Stuart Hall (2003a: 339), pelas "estratégias culturais capazes de fazer a diferença". Nestas, o papel da corporalidade e das sonoridades é fundamental, inclusive por permitir a transmissão de saberes e experiências, cuja "tradução" em palavras é difícil ou resulta numa síntese de outra ordem.

\footnotetext{
${ }^{20}$ O frevo é um tipo de marcha sincopada, que tem uma presença muito importante no Carnaval pernambucano. Caboclinhos é um folguedo reminiscente das danças apresentadas pelas populações indígenas durante as procissões ou paradas militares no Brasil colonial.

${ }^{21}$ Entrevista concedida a esta autora em Fevereiro de 1999.

22 Ver, por exemplo, Giddens (1984).
} 


\section{Paisagens sonoras}

A utilização da metáfora da paisagem para descrever os contextos culturais permite analisar continuidades e descontinuidades e pensar o intercruzamento de elementos diversos para formar conjuntos de referências, símbolos e significados característicos de meios culturais específicos. Uma das formulações dessa metáfora - soundscape (paisagem sonora) - foi elaborada nos anos 1970 pelo musicólogo canadense Murray Schafer (2001) e aplica-se mais especificamente aos conjuntos sonoros que marcam os diferentes ambientes humanos. Mais recentemente, Appadurai (2004) formulou, a partir da palavra landscape (paisagem) a definição dos principais cenários nos quais se desenrolam os processos de mundialização, utilizando a noção de mediascape (paisagem mediática) para descrever todo o universo simbólico criado pelos media, que se apresenta como um dos meios em que o imaginário social se move.

Embora a formulação de Schafer inclua as sonoridades produzidas natural ou culturalmente e, assim, não se restrinja à música, permite pensar na especificidade (ou não) das sonoridades que contribuem para marcar fronteiras entre identidades e espaços culturais distintos. Tem relevância para se compreender a pertinência das definições de estilos musicais locais ou regionais, bem como as características próprias do ambiente sonoro, de um ponto de vista mais amplo, contrariando a "surdez" muitas vezes presente (pela ausência da escuta como método de investigação) nas ciências sociais, fundamentalmente pelo primado de epistemologias racionalistas, inclusive nos estudos sobre as cidades (Fortuna, 1999 e 2001).

Num sentido oposto, a noção de mediascape permite pensar as realidades e conteúdos transnacionais, presentes nas relações sociais em ampla escala, constituindo-se num instrumento para analisar os conteúdos divulgados mundialmente pela indústria cultural e que formam o que Renato Ortiz denominou de cultura ou memória internacional-popular. ${ }^{23}$ As sonoridades constituem-se também como marcos quotidianos da cultura internacional-

\footnotetext{
${ }^{23}$ A noção de culturalmemória internacional-popular remete para um conjunto de processos associados à emergência de referências culturais mundializadas e desenraizadas em relação aos contextos nacionais. A desterritorialização da cultura está ligada à própria deslocalização da produção no contexto da acumulação flexível e conjuga-se com a crescente importância do consumo na recriação de laços sociais esgarçados pela modernidade. Ortiz refere-se a essa memória como uma memória cibernética, portadora dos traços da modernidade-mundo, que permite o reconhecimento ou a sensação de familiaridade de objectos próximos, mesmo em um ambiente estranho. Os conteúdos dessa memória são as estrelas de cinema, os carros, as marcas de cigarro, o rock, "personagens, imagens, situações veiculadas pela publicidade, histórias em quadrinhos, televisão, cinema" (Ortiz, 1994: 125-126).
} 
-popular, como a "[...] marca sonora do levantamento automático de dinheiro ou o som universal do pagamento com cartão de crédito, quer estejamos em Coimbra ou em São Paulo, em Maputo ou Nova Iorque" (Fortuna, 1999: 116).

Dadas as características das culturas urbanas nas metrópoles brasileiras (mas não exclusivamente destas), pode-se dizer que suas paisagens sonoras se encontram marcadas pela cultura internacional-popular, contando, no campo musical, com uma presença intensa dos géneros mundializados, destacando-se o rock, o pop, o funk e outros géneros daí derivados como o hip-hop, o ska, o dub. Em síntese, destaca-se um conjunto de géneros musicais que valorizam o ritmo, o pulso, a batida e que apresentam suficiente plasticidade para serem adaptados aos contextos locais, seja nas suas versões "canónicas" ou por meio da produção de novas formas híbridas. Muitos estudos já têm destacado a plasticidade e as possibilidades de apropriação do pop/rock em contextos locais, género que veio a se constituir num pano de fundo ou numa linguagem que, por estar no ouvido de todos, permite a comunicação translocal. Como sintetiza José Miguel Wisnik (1989: 98), o estado da música actual é de simultaneidade: "O rock é a superfície de um tempo que se tornou polirrítmico. Progresso, regressão, retorno, migração, liquidação, vários mitos do tempo dançam simultaneamente no imaginário e no gestuário contemporâneos, numa sobreposição acelerada de fases e defasagens".

A dita "universalidade" do rock (e dos géneros seus tributários) está ligada ao facto de ele fazer parte da cultura internacional-popular e veicular, junto com a música, um conjunto de práticas, um repertório de sensibilidades, de expressões corporais e de emoções institucionalizadas. Estes traços se tornaram parte de um tipo de capital cultural e um babitus dominante no campo da música popular. Pode-se dizer que "a predominância global da estética do rock para fazer música local é uma manifestação primordial da lógica cultural da globalização" (Regev, 1997: 137). Assim, faz parte da própria dinâmica do rock a dialéctica entre homogeneização/padronização e heterogeneização/diversificação, que se dá, inclusive, pelo processo de incorporação de sonoridades locais ou de "etnicização" da música, como dizem alguns.

Se, de alguma maneira, é possível afirmar que o movimento mangue lidou com as tradições locais de forma positiva, isto ocorre porque estas foram tratadas como cultura viva e presente no quotidiano, e não como folclore, tradição passada e fossilizada. As ideias de articular um "núcleo de pesquisa e produção de ideias pop", conectar "as boas vibrações dos mangues com a rede mundial de circulação de conceitos pop", injectar energia nas 
"veias obstruídas" da cidade ${ }^{24}$ precisavam apenas de um pequeno impulso. O manguebeat, com seu aspecto colectivista e com a valorização do "faça você mesmo", contribuiu para fazer emergir a produção cultural que já se vinha formando na década anterior. Aos jovens do Recife, faltavam apenas os meios para ganhar visibilidade pública, que foram criados pela mobilização de significados profundamente enraizados no imaginário social da cidade. Assim, a relação que se estabeleceu entre as formas estéticas tradicionais e contemporâneas levou a uma maior proximidade entre gerações, estilos culturais tidos como antagónicos e movimentos socioculturais de diversos matizes, dinamizando todo um sector de produção e difusão artística. Como disse Chico Science, "modernizar o passado é uma evolução musical" ${ }^{25}$ Nas palavras do pesquisador Philip Galinsky (2002: 89):

A fusão, pelo mangue, de traços, instrumentos e mesmo de costumes das tradições populares regionais com o pop contemporâneo estrangeiro recaracteriza, sem dúvida, essas tradições populares como modernas - e o faz criticamente, sem deixá-las perderem suas identidades. E, ao mesmo tempo, ao utilizar elementos musicais modernos, estrangeiros, no pop brasileiro, os grupos do mangue também reafirmam esses elementos como sendo até mais tradicionais - ou seja, como parte da tradição brasileira. Este processo de interpenetração, em que a distinção entre categorias estabelecidas é questionada, é um dos principais aspectos do mangue e da cena de Recife. O mangue poderia ser pensado como um retorno paradoxal ao tradicional através da modernização.

Um aspecto a chamar à atenção nestas considerações é o que Galinsky chama de incorporação crítica das tradições, qualificação que se justifica pelo facto das diversas bandas ligadas ao movimento mangue integrarem os elementos tradicionais contextualizando-os no tempo e no espaço (de "Pernambuco falando para o mundo", ${ }^{26}$ no alvorecer do $3^{\circ}$ milénio). Assim, as formas musicais resultantes da mistura escapam ao pastiche e à paródia, recursos habitualmente utilizados nas manifestações da produção cultural dita pós-moderna (cf. Jameson, 1996).

Contudo, talvez a definição do retorno ao tradicional através da modernização como "paradoxal" seja tributária de uma concepção do popular como algo "original” e pouco aberto à transformação e ao diálogo inter-

\footnotetext{
${ }^{24}$ Fragmentos do manifesto Caranguejos com cérebro, reproduzido no encarte do CD Da lama ao caos.

${ }^{25}$ Verso inicial de "Monólogo ao pé do ouvido", canção de abertura do CD Da lama ao caos.

${ }^{26}$ Este era o slogan da mais moderna estação de rádio brasileira à época de sua inauguração (1948), a Rádio Jornal do Commercio, situada no Recife.
} 
cultural, ainda mais se considerarmos uma certa ambiguidade na caracterização do que é tradicional. Ao afirmar que a incorporação de elementos musicais estrangeiros no pop brasileiro é uma "moderna tradição" - e até se poderia considerar assim no caso de algumas expressões híbridas, como no caso do Tropicalismo -, utiliza-se um procedimento de inversão do que é normalmente considerado "tradicional" ou "moderno". A afirmação é inexacta e não encontra ressonância entre os especialistas no campo ${ }^{27}$ da música popular brasileira. A identificação entre o estrangeiro e o "moderno" pediria uma qualificação mais precisa, pois nem todas as influências ou géneros estrangeiros (como o bolero e a música ligeira italiana, para citar apenas dois exemplos) são considerados pelos críticos e historiadores da MPB como modernizantes. Também em leituras que enfatizam o vínculo entre produção musical e classe social (na concepção marxista), a incorporação de influências estrangeiras, quando não correspondem às condições materiais de existência de uma determinada classe, pode ser vista como heteronomia. A "modernização" - se é que o termo se aplica no caso - da "tradição" promovida pelo mangue não é tão paradoxal assim, por dois motivos: 1) pelas transformações recentes nas paisagens sonoras globais; 2) pelas características estéticas da música tradicional nordestina, que se harmonizam facilmente com essas transformações.

É importante lembrar que os dois processos se desenvolvem simultaneamente. Quanto ao primeiro ponto, por um lado, há uma sobrecarga do sentido de audição, sobretudo no meio urbano, pela constante presença da música de todos os géneros (junto com os mais diversos ruídos) em todos os espaços e com a constante repetição de canções de sucesso pelos mais diversos meios. Por outro lado, a própria música ocidental tonal (de concerto) passa, há várias décadas, por um processo de esgotamento criativo, dando lugar a uma música pós-tonal; soma-se a isto a difusão do pop/rock, que acaba por trazer o retorno da música modal (pré-tonal), caracterizada pelo pulso (Wisnik, 1989). Quanto às características da música nordestina, alguns investigadores já apontaram para a sua grande plasticidade, força e possibilidade de diálogo com as formas contemporâneas (modais), sobretudo pelo uso da terça neutra. ${ }^{28}$

\footnotetext{
${ }_{27}$ Utiliza-se a noção de campo aqui no sentido definido por Bourdieu (1983), como espaço de disputa entre agentes e/ou instituições pelo monopólio da autoridade, considerando-se um capital (no caso, cultural) específico.

${ }_{28}$ As escalas utilizadas pela música tonal baseiam-se no sistema temperado, que, ao adoptar "uma afinação uniforme e homogênea", contraria "as propriedades acústicas dos intervalos 'naturais'”, igualando os intervalos entre os sons. Assim, o espaço de uma oitava (de dó a dó, por exemplo), é dividido em 12 notas com iguais distâncias entre elas, 12 semitons, as sete teclas brancas e as
} 
Daí a importância de escutarmos as paisagens sonoras locais, que, obviamente, não são constituídas apenas pelos conteúdos sonoros mundializados. No caso do Recife e do seu contexto regional, a pesquisa etnomusicológica identifica determinadas características que marcam o conjunto de suas sonoridades. Tiago de Oliveira Pinto estudou, entre muitas outras manifestações musicais, as músicas de pífaros e da pequena gaita dos grupos de caboclinhos de Pernambuco e da Paraíba. Em relato posterior de uma pesquisa realizada nos anos 1980, afirma que verificou:

a constância de um elemento de afinação destes instrumentos que têm na terça neutra um recurso básico, que transcende o puramente estilístico. A remoção das terças maior ou menor das melodias, e a inserção, ao invés delas, da terça neutra, toma do repertório nordestino das flautas o jugo dos modos maior ou menor, sem os quais, lembre-se, não existiria a música do ocidente, baseada na tonalidade e harmonia funcional. (Pinto, 2001: 242)

É importante lembrar, como faz o investigador, que essa produção musical - tal como grande parte da música tradicional não ocidental, de carácter modal - apresenta aspectos sonoros que vêm sendo retomados com o esgotamento da música tonal. Esta perspectiva permite escapar das concepções impregnadas de ecos evolucionistas, que hierarquizam as sonoridades com base nas concepções musicais e noções de maior ou menor complexidade de acordo com a quantidade de informação, fixadas pela estética clássica ocidental. Referindo-se à paradoxal actualidade da música modal de várias tradições (africanas, orientais e mesmo europeias), José Miguel Wisnik afirma que:

Encontram-se nelas realizações vocais, rítmicas, polifônicas, timbrísticas similares àquelas que a linguagem da música contemporânea buscou realizar, nem sempre com a mesma força [...]. O impasse da idéia de uma progressão permanente da linguagem musical como organização das alturas melódico-harmônicas encurva subitamente a história musical, fazendo com que a música pós-tonal se encontre [...] em estado de deslocada e estimulante sincronia com as músicas pré-tonais. Esse ponto de encontro se dá numa concepção de tempo não-linear que retorna ao princípio do pulso. (Wisnik, 1989: 96-97)

cinco pretas de um piano (Wisnik, 1989: 130-131). No sistema tonal, é fundamental a diferenciação entre as escalas/modos menores e maiores, distintas sobretudo pela presença da terça menor ou maior, sendo a primeira definida por um intervalo de três semitons e a segunda, de quatro. A terça neutra é um intervalo intermediário entre a terça maior e a menor e, logo, não pertence ao sistema temperado. 
Estas percepções acerca dos (des)caminhos da música ocidental e da forma como as sonoridades não ocidentais se tornaram nossas contemporâneas permitem-nos escutar, com maior atenção, as características sonoras específicas que, do ponto de vista da audição, possibilitam a comunicação com públicos distintos e o deslocamento das fronteiras entre o popular, o erudito e o "de massa". Mais uma vez, é importante ressaltar a singularidade das realizações musicais nordestinas, que utilizam intervalos não temperados, de modo a não demarcar uma tonalidade maior ou menor. Esta característica é, aliás,

assunto para festivais de música de vanguarda, atonal e de pouca aceitação do público de massa. No entanto, as bandas de pífanos do nordeste, os aboios, as trovas dos repentistas, as toadas de caboclinhos, os forrós pé de serra, todo este vasto repertório é caracterizado pela terça neutra. A conclusão que se tira deste fenómeno sugere uma explicação possível para a força das manifestações culturais do nordeste, mesmo quando fora de seu contexto. (Pinto, 2001: 242)

Esse elemento marcante da paisagem sonora nordestina - "a terça neutra como aspecto peculiar de afinação" - está profundamente relacionado com a visão de mundo da população que a produz e inclui certos procedimentos como a utilização conjunta de instrumentos com intervalos diatónicos temperados, como o acordeão, e instrumentos e estilos vocais caracterizados pela terça neutra. Como conclui Pinto:

Esta simultaneidade, que, aparentemente, não cria atritos intransponíveis, contradizendo assim tudo o que pregam as teorias musicais do ocidente, denota a abertura com que estruturas tradicionais da sociedade no Nordeste abarcam elementos da globalização, sem por isso destruir ou renegar os conceitos próprios mais genuínos. (Pinto, 2001: 243)

A partir dessas afirmações, pode-se salientar que é infundado o temor, que se manifestou também no contexto do Recife, da descaracterização da cultura popular pela influência do e/ou mistura com o pop internacional. Digo temor infundado tanto por considerar as características específicas da música do Nordeste brasileiro descritas acima, como por conceber a cultura (e a música) popular como um terreno em constante transformação (e, portanto, não congelado ou cristalizado em formas cuja "pureza" deva ser mantida a todo o custo), onde se realizam disputas sobre a hegemonia cultural. Como define Stuart Hall:

A cultura popular não é, num sentido 'puro', nem as tradições populares de resistência a esses processos [de 'moralização' das classes trabalhadoras, de 'desmoralização' 
dos pobres e de 'reeducação' do povo], nem as formas que as sobrepõem. É o terreno sobre o qual as transformações são operadas. (Hall, 2003b: 248-249).

Pretende-se concluir estas reflexões discutindo um pouco a forma como esse terreno de disputa sobre o popular vai sendo atravessado por diferentes estratégias de (re)construção identitária, que significam também um reposicionamento das culturas populares no contexto social mais amplo.

\section{A vertigem e a busca de um eixo}

Não retomarei aqui a vasta discussão que se tem feito nas ciências humanas sobre a crise das identidades e a mistura de estilos no contexto do pós-moderno global (cf. Connor, 1992; Featherstone, 1995; Hall, 1999; Huyssen, 1991). Relembrarei, apenas, que a presença avassaladora dos conteúdos mundializados nos variados contextos locais ou regionais tem levado também a formas de construção de identidades que vão buscar os seus conteúdos em circuitos externos ao mercado cultural global, ou seja, fora do "supermercado de estilos" que se encontra aberto para aqueles que podem escolher. Entendo esse processo, tal como alguns autores, como sendo parte das tensões entre o local e o global, entre homogeneização e heterogeneização, inerentes às novas articulações entre, por um lado, significados e espaços definidos e, por outro, misturas e (des)localizações na cultura contemporânea, mediadas pelas novas tecnologias da informação. Convém lembrar que essas tensões ocorrem em contextos sociais profundamente desiguais, o que, no caso dos processos de construção identitária e de estilos de vida, impõe limites estruturais bastante estreitos para a maioria dos indivíduos.

Diante da oferta vertiginosa de símbolos e bens culturais, verifica-se, simultaneamente à adopção de estilos de vida mundializados e desterritorializados, a busca de expressões culturais que religam certos segmentos sociais às tradições locais ou, noutros casos, às tradições tomadas de empréstimo a certas "comunidades". Para reflectirmos sobre os variados sentidos que as relações com a cultura popular adquirem para os diversos segmentos sociais, é interessante retomar um dos depoimentos de Chico Science, acerca da sua relação com a cultura local, envolvendo a sua própria história de vida e vivência das manifestações populares, que encontra paralelo nas histórias de vida de outros músicos da cena mangue:

Quando eu era bem mais novo, lá pelos doze anos, dançava ciranda... Meus pais tinham uma ciranda... eu já dancei ciranda na praia, no bairro e vi os maracatus também. Assisti na minha infância aos maracatus fazendo o acorda-povo, que acon- 
tece na época do São João, sempre lá pela meia-noite... então eu vi todas essas coisas que nos ensinaram como folclore, como uma manifestação já passada, mas que não é bem dessa maneira que você tem que ver. Existem ritmos ali que pode aprender a tocar porque é da sua terra, é do Brasil, é uma coisa que você entende - é a tua língua. (apud Teles, 2000: 277)

Vários elementos chamam a atenção no depoimento, entre os quais se destacam dois: a vivência e a concepção de cultura popular. Em primeiro lugar, a memória de sua vivência da ciranda e do maracatu mostra que a cultura popular era para ele, assim como é para outros da mesma geração, algo palpável e incorporado de modo involuntário por meio da experiência quotidiana: "é a tua língua". Em segundo lugar, salta aos olhos sua concepção da cultura popular como manifestação viva, que contrasta com outras concepções que a definiriam como "folclore" ou "manifestação passada".

É curioso notar, entretanto, que essa forma de relação com o popular, considerado como manifestação dinâmica e presente, vem aparecendo como recurso identitário entre certos segmentos das camadas jovens urbanas, sobretudo os de classe média e mais intelectualizados, pessoas para as quais as tradições populares voluntariamente procuradas são, na maioria das vezes, totalmente alheias à sua experiência social imediata. Referindo-se ao contexto do Rio de Janeiro, Elizabeth Travassos (2004: 229) salienta que: "Hoje, quando a recriação urbana de 'danças folclóricas' entusiasma estudantes, artistas jovens, militantes de movimentos sociais e até os media, um certo tipo de umbigada - sensual, delicada, livre de censura moral - reaparece nas capitais".

A autora interpreta esse "reaparecimento" da umbigada - associada à música e dança populares de origem africana, perpetuadas em várias manifestações da cultura popular brasileira - como parte de um conjunto de processos de construção identitária que, actualmente, vêm lançando mão de manifestações antes residuais da cultura popular "como recursos simbólicos na política das culturas” (Travassos, 2004: 248). Vários ritmos e danças tradicionais populares brasileiras tiveram um impulso renovado, principalmente a partir dos anos 1990, sob efeito de transformações em dois âmbitos: 1) na reorganização dos herdeiros dos saberes tradicionais, agora impulsionados também pelo sucesso comercial das produções híbridas e das suas formas próprias de criação cultural; 2) na mercantilização das culturas populares em associação ao turismo, com a valorização do património material e imaterial (ganhando este último uma importância anteriormente rara) como elemento de atracção de turistas, inclusive no caso das cidades que, sem a valorização do património imaterial, dificilmente seriam consi- 
deradas sítios turísticos. Estas foram duas inflexões fundamentais para trazerem para o primeiro plano as culturas populares como elementos de identificação de certas parcelas da juventude.

Outras manifestações culturais com o mesmo carácter das danças de umbigada (também mencionadas por Travassos) e utilizadas nos mesmos processos de identificação social são o samba de roda do Recôncavo Baiano, todo o calendário festivo incluindo bois e tambores no Maranhão, o coco no litoral nordestino, os batuques, jongos e tambores no Rio de Janeiro, em São Paulo e em Minas Gerais. Poder-se-iam citar muitas outras expressões ou festas populares que acontecem pelo Brasil afora.

Maria Celeste Mira (2006) analisa manifestações do mesmo tipo, procurando situá-las no contexto das transformações económicas e sociais mais amplas e no circuito da cultura popular na cidade de São Paulo, incluindo as organizações não governamentais que fazem a mediação entre as "comunidades" populares e o público urbano. Comentando alguns trabalhos académicos, que fazem etnografia e análises de festas populares e que constatam a adesão da juventude às manifestações da cultura popular (incluindo tanto a participação em grupos de dança e música, como o consumo de artesanato e de outros produtos, como CDs e filmes), a autora aponta para dois motivos primordiais que estariam na base do impulso das classes médias e altas urbanas, sobretudo as mais intelectualizadas, nesta direcção:

1) "[...] a busca da distinção de classe, não apenas associada ao luxo, mas à participação num grupo estético privilegiado, antenado, que antecipa a moda" (Mira, 2006: 368); ou seja, a adopção de estilos de vida que permitem colocar em evidência uma certa "originalidade" ao distanciar-se do consumo massificado;

2) a busca de referenciais culturais mais "sólidos" num contexto social de risco e insegurança $;{ }^{29}$ ou, dito de outro modo, a busca de "[...] convivências com as 'comunidades', com os seus líderes, senhores e senhoras de cabelos brancos que lhes transmitem ensinamentos que a vida moderna não oferece" (Mira, 2006: 372).

Embora a maioria dos grupos de cultura popular ou das organizações não governamentais a eles associadas não possam ser considerados "comuni-

\footnotetext{
${ }^{29}$ A ideia de "comunidade" e o discurso comunitário ganharam força nas últimas décadas justamente porque, segundo Bauman, se relacionam com a busca de segurança frente à "vertigem" da modernidade tardia. Nas palavras de Bauman (2003: 128): "Hoje em dia, a comunidade é procurada como abrigo contra as sucessivas correntezas de turbulência global - correntezas originadas em lugares distantes que nenhuma localidade pode controlar por si só”.
} 
dades" no sentido sociológico do termo - como, aliás, nos lembra a autora o que importa é que representam um ideal de "comunidade" para os "simpatizantes", aqueles que se relacionam com estes meios e com actividades por elas proporcionadas. Assim, o envolvimento activo com grupos de cultura popular pode ser bem compreendido no quadro das reacções às pressões no sentido da homogeneização e da padronização, relacionadas às estratégias de distinção, bem como com as construções de novas formas de pertença e solidariedade social.

No entanto, é importante ir além dessas constatações e compreender que tipo de ligação com as "comunidades" emerge nas relações acima descritas. Com este intuito, Mira retoma a reflexão de Bauman (2003) acerca de dois tipos de comunitarismo presentes no cenário actual: a "comunidade estética" e a "comunidade ética". Os dois tipos de comunitarismo estão relacionados às realizações desiguais das promessas da modernidade quanto à objectivação dos direitos individuais. A "comunidade estética" procura conciliar os princípios da liberdade com o poder de vinculação dos indivíduos. Está fortemente ligada à constituição dos estilos de vida e ao entretenimento e baseada em ídolos de massa ou em preocupações comuns, compartilhadas temporariamente. Por evitarem compromissos de longo prazo entre os indivíduos que delas participam, as "comunidades estéticas" estão em sintonia com o descaso em relação à diferença social, cultivado pela "nova elite global", nos termos de Bauman.

A adesão às "comunidades estéticas" é uma prerrogativa dos indivíduos de facto, que podem escolher o seu próprio destino. Bauman refere-se ao cosmopolitismo da "elite global" como sendo selectivo e, basicamente, redutor das diferenças ao mínimo de impacto. O hibridismo não faz parte dos seus procedimentos ou das suas vivências quotidianas: sua absorção das culturas populares ocorre pelo consumo de produtos que passaram por um "refinamento", que, por sua vez, é fruto da intervenção de profissionais (designers, produtores musicais, etc.) encarregados de "depurar" os conteúdos mais abertamente expressivos das diferenças. Nestes casos, a relação que se cria é, fundamentalmente, baseada na "solidariedade de mercado". Como pergunta Mira, será que os produtos derivados das culturas populares continuarão a ser vendidos depois de passar a moda do "popular", ou, dito de outro modo, depois de passar a possibilidade de funcionarem como signos de distinção?

Já as "comunidades éticas" se baseiam em vínculos mais fortes. Implicam o estabelecimento de compromissos a longo prazo, direitos inalienáveis e obrigações inexoráveis. O seu lado positivo é a garantia do amparo colectivo diante desse mundo de indiferença e risco. A construção deste tipo de 
“comunidade" é a única opção aberta aos indivíduos de jure, para os quais as promessas de liberdade da modernidade nunca se realizaram, tendo existência apenas no plano formal. No caso das organizações não governamentais dedicadas à divulgação da cultura popular e da juventude a elas relacionadas, Mira vê a possibilidade de criação de "comunidades éticas", sobretudo pelo engajamento com os movimentos pela paz. Para além da criação, paira a dúvida acerta da permanência temporal dessas "comunidades éticas" baseadas nas identificações emergentes com as culturas populares.

$\mathrm{Na}$ investigação sobre o contexto do Recife, foi possível verificar a existência de outros tipos de construção de "comunidades éticas" ligadas à cultura popular, que, no caso do manguebeat e das colectividades dinamizadas pelo movimento, envolviam directamente os mestres produtores da cultura popular em processos de reivindicação dos direitos à igualdade (direito à educação, acesso à cultura, melhoria das condições de vida, criação de emprego ou de cooperativas, criação de bases materiais para a produção cultural e para a perpetuação das próprias "comunidades"). Essa construção ocorreu também pela transformação da cultura popular em produto (desejado), veiculado pela indústria cultural. Mas não só: as solidariedades locais foram mobilizadas para a dinamização de projectos que não passaram exclusivamente pela transformação da cultura em mercadoria, contribuindo para a utilização da cultura como instrumento de auto-expressão e reivindicação de direitos. É o caso do projecto Alto Falante, mencionado páginas atrás, e de alguns outros projectos desenvolvidos na Região Metropolitana do Recife (cf. Mendonça, 2004), bem como em outras localidades. Nesse contexto, afirmou-se a cultura popular como campo de luta, dentro do qual não há determinações a priori quanto aos equilíbrios de poder e à projecção pública de significados.

\section{Conclusão}

Apontou-se, por meio dos exemplos e da análise, para o papel sui generis que as culturas populares vêm adquirindo no contexto contemporâneo. Sobretudo no caso dos sons, este papel deve-se às próprias características de certas expressões populares, quando compreendidas no conjunto da produção musical e das ressignificações dos usos da cultura nas últimas décadas, como se viu no contexto da música do nordeste brasileiro em geral e, mais especificamente, de Pernambuco.

Do ponto de vista da estética musical e dentro dos processos de reorganização do campo cultural, sonoridades marcadas pelo pulso fazem encontrarem-se diferentes vertentes - os desenvolvimentos da música de concerto, 
da canção ligeira e das canções tradicionais populares - num campo onde as fronteiras se desvanecem. A observação das transformações concretas permite dizer que alguns diálogos se estabelecem para além das fechadas instâncias de consagração e distinção, como definidas por Bourdieu ${ }^{30}$, em favor da busca de homologias estruturais estético-musicais mais profundas, o que resulta numa reorganização das hierarquias culturais. Convém lembrar que as trocas que transcendem fronteiras só podem ocorrer em um contexto mais geral de mudanças na esfera das políticas e da economia da cultura, que, entre outros redireccionamentos, passaram a apoiar as expressões populares tradicionais principalmente como elemento de valorização dos lugares e de renovação da produção da indústria cultural.

No caso do manguebeat, possibilidades bastante variadas de hibridismo foram mobilizadas para a criação de expressões musicais diversas, em que a conjunção entre o pop e o popular resultou num enriquecimento de ambos os campos. Isto ocorreu porque, por um lado, inovações foram de facto produzidas com a criação dessas formas híbridas. Entretanto, as ambiguidades características da relação entre a indústria fonográfica e a produção musical "alternativa" também se manifestaram em relação ao manguebeat, pois essas formas foram posteriormente apropriadas e transformadas em fórmulas: o que soava novo quando a Nação Zumbi, a Mundo Livre S/A e outras bandas alcançaram projecção pública, acabou por se rotinizar por sua utilização ad nauseam por outras bandas e artistas. Por outro lado, a boa aceitação por parte do público dessas formas híbridas criou um ambiente de valorização e aceitação das expressões populares enquanto tais. A gravação de CDs de mestres populares pernambucanos, como Mestre Salustiano, D. Selma do Coco e Lia de Itamaracá, que passaram a ser vistos também como produtores de uma mercadoria com apelo comercial, é um dos indícios desse facto. Do mesmo modo, a metáfora do mangue como sinónimo de diversidade cultural foi apropriada pelos órgãos oficiais de promoção do turismo, que passaram a dar visibilidade à ampla oferta de manifestações tradicionais.

Do ponto de vista da reorganização e ressignificação das identidades, verifica-se a existência de uma pluralidade de processos associados à formação de "comunidades estéticas" e de "comunidades éticas", que, no segundo caso, têm também impacto sobre o plano da cidadania e da soli-

\footnotetext{
${ }^{30}$ Featherstone (1995), entre outros autores, alerta para a necessidade de reformular algumas concepções bourdianas à luz das transformações sociais mais recentes e da investigação empírica a seu respeito, apesar da importância da elaboração teórica em torno da noção de campo para se compreender a interacção entre as diversas instâncias da sociedade e, dentro do campo cultural, os factores estruturais que levam a uma organização específica.
} 
dariedade social. A valorização das "comunidades" tradicionais por meio da projecção da cultura que produzem vem reforçar, como já se afirmou, o sentimento de auto-estima e os laços internos dessas colectividades, além de propiciar a aproximação de sujeitos sociais, como alguns segmentos da juventude universitária e/ou de classe média e alta, que constroem vínculos de solidariedade em relação a estes grupos. Esses vínculos, motivados num primeiro momento pelo desejo de fruição e de engajamento com a produção da cultura popular, produzem, por um lado, identificações alternativas aos estilos de vida baseados na "solidariedade de mercado" e, por outro, formas de solidariedade social em relação aos grupos populares.

No caso de Recife, foram ressignificadas não só as identidades colectivas dos grupos populares. As próprias imagens de alguns bairros (como se exemplificou no caso do Alto Zé do Pinho) e da cidade como um todo passaram por um profundo processo de transformação, que seguiu pari passu a valorização da diversidade cultural local e a animação dos lugares, como o Bairro do Recife, centro histórico da cidade e lugar fundamental de referência de sua identidade urbana. Por oposição à sua imagem tradicional (bastante edulcorada), de acordo com a qual Recife é conhecida como a Veneza Brasileira, propagou-se a imagem da Manguetown ("cidade do mangue, incrustrada na lama dos manguezais, onde estão os homens-caranguejo"31), mais próxima da realidade contraditória da capital pernambucana.

Não se pode prever se a moda do popular vai passar. Mas, por enquanto, vem gerando frutos positivos em termos de reorganização das hierarquias culturais, de reconhecimento dos saberes populares, da busca da efectivação dos direitos de cidadania (mesmo que pontualmente) e da construção de relações transversais entre sujeitos de diferentes classes sociais.

\section{Referências bibliográficas}

Appadurai, Arjun (2004), Dimensões culturais da globalização. A modernidade sempeias. Lisboa: Teorema.

Bauman, Zygmunt (2003), Comunidade: a busca por segurança no mundo atual. Rio de Janeiro: Jorge Zahar.

Bourdieu, Pierre (1983), Lições de Sociologia. São Paulo: Marco Zero.

Burke, Peter (2003), Hibridismo cultural. São Leopoldo: Ed. Unisinos.

Canclini, Nestor Garcia (1997), Culturas híbridas. São Paulo: Edusp.

Cascudo, Luís da Câmara (1988), Dicionário do folclore brasileiro. Belo Horizonte: Itatiaia; São Paulo: Edusp. [6ª ed.; 1954]

${ }_{31}$ Trecho da canção "Antene-se", $9^{a}$ faixa do CD Da lama ao caos. 
Connor, Steven (1992), Cultura pós-moderna. Introdução às teorias do contemporâneo. São Paulo: Loyola.

Crane, Diana (2002), "Culture and Globalization. Theoretical Models and Emerging Trends”, in Diana Crane; Nobuco Kawashima; Ken’ichi Kawasaki (orgs.), Global Culture. Media, Arts, Policy and Globalization. New York: Routledge, 1-25.

Featherstone, Mike (1995), Cultura de consumo e pós-modernismo. São Paulo: Studio Nobel.

Folha de São Paulo (2005), “Orquestra Manguefônica recria 'Da lama ao caos'”, Folha de São Paulo (Guia da Folha), 13/1/2005.

Fortuna, Carlos (1999), "Paisagens sonoras. Sonoridades e ambientes sociais urbanos", in C. Fortuna, Identidades, percursos, paisagens culturais. Estudos sociológicos de cultura urbana. Oeiras: Celta, 103-117.

Fortuna, Carlos (2001), "Soundscapes: the Sounding City and Urban Social Life", Oficina do CES, 161.

Galinsky, Philip A. (2002), 'Maracatu Atômico': Tradition, Modernity, and Post-Modernity in the Mangue Movement of Recife, Brazil. New York: Routledge.

Giddens, Antony (1984), The Constitution of Society. Outline of the Theory of Structuration. Cambridge: Polity Press.

Hall, Stuart (1999), A identidade cultural na pós-modernidade. Rio de Janeiro: DP\& A. [3 $3^{\mathrm{a}}$ ed.]

Hall, Stuart (2003a), “Que 'negro' é esse na cultura negra?”, in Liv Sovik (org.), Da diáspora: Identidades e mediações culturais. Belo Horizonte: UFMG; Brasília: Representação da UNESCO no Brasil, 335-349.

Hall, Stuart (2003b), “Notas sobre a desconstrução do 'popular'”, in Liv Sovik (org.), Da diáspora: Identidades e mediações culturais. Belo Horizonte: UFMG; Brasília: Representação da UNESCO no Brasil, 247-264.

Huyssen, Andreas (1991), "Mapeando o pós-moderno”, in Heloísa Buarque de Hollanda (org.), Pós-modernismo e política. Rio de Janeiro: Rocco, 15-80.

Jameson, Fredric (1996), Pós-modernismo. A lógica cultural do capitalismo tardio. São Paulo: Ática.

Magnani, José Guilherme C. (2002), "De perto e de dentro: Notas para uma etnografia urbana”, Revista Brasileira de Ciências Sociais, 17(49), 11-29.

Mendonça, Luciana F. M. (2004), Do mangue para o mundo: o local e o global na produção e recepção da música popular brasileira. (Tese de doutoramento) Campinas: Unicamp.

Mira, Maria Celeste (2006), "Ongueiros, festeiros e simpatizantes: o circuito urbano da 'cultura popular' em São Paulo”, in Heitor Frúgoli Jr. et al. (org.), As cidades e os seus agentes: práticas e representações. Belo Horizonte: PUC Minas; São Paulo: Edusp, 353-376.

Ortiz, Renato (1994), Mundialização e cultura. São Paulo: Brasiliense. 
Pinto, Tiago de Oliveira (2001), "Som e música. Questões para uma antropologia sonora”, Revista de Antropologia, 44(1), 221-286.

Regev, Motti (1997), "Rock Aesthetics and Music of the World", Theory, Culture E Society, 14(3), 125-142.

Santiago, Vandeck (2001), "Do mangue ao mito”, Continente Multicultural, 3. Disponível em http://www.continentemulticultural.com.br/. Acesso em Dezembro de 2003.

Schafer, R. Murray (2001), A afinação do mundo. São Paulo: Editora UNESP [1977].

Teles, José (2000), Do frevo ao manguebeat. São Paulo: Editora 34.

Travassos, Elizabeth (2004), "Por uma cartografia ampliada das danças de umbigada", in José Machado Pais et al. (org.), Sonoridades luso-afro-brasileiras. Lisboa: Imprensa de Ciências Sociais/ICS, 227-253.

Van Der Lee, Pedro (1998), "Sitars and Bossas: World Music Influences”, Popular Music, 17(1), 45-70.

Williams, Raymond (1979), Marxismo e literatura. Rio de Janeiro: Zahar.

Wisnik, José Miguel (1989), O som e o sentido. Uma outra história das músicas. São Paulo: Companhia das Letras.

Wisnik, José Miguel (1997), "Música, problema intelectual e político. Entrevista a Ozeas Duarte e Paulo Baía”, Teoria E Debate, 35, 58-60.

\section{Discografia}

Chico Science, Fred Zero Quatro, Siba, Lúcio Maia e Paulo Rafael (prod.), Baile Perfumado (Banda sonora do filme, dirigido por Paulo Caldas e Lírio Ferreira). Natasha Records, 1997.

Chico Science \& Nação Zumbi, Da lama ao caos. Sony Music, 1994.

\section{Internet (Fontes audiovisuais)}

Chico Science \& Nação Zumbi, Videoclipe da canção “A cidade" - http://www.youtube. $\mathrm{com} /$ watch? $=\mathrm{qfZf} \times \mathrm{xC} 8 \mathrm{bSTQ} \&$ feature $=$ related

Chico Science \& Nação Zumbi, Videoclipe da canção “Sangue de bairro" - http://www. youtube.com/watch?v=Brb7ssvasNY\&feature=related

Devotos, Videoclipe da canção “Dia morto" - http://www.youtube.com/watch?v=xC UFvVMCVOo\&feature $=$ related

Devotos, Videoclipe da canção "Tudo faz sentido" - http://www.youtube.com/ watch?v=_rIJfq5gXL4\&feature $=$ related

Mundo Livre S/A, Videoclipe da canção "Livre iniciativa" - http://www.youtube.

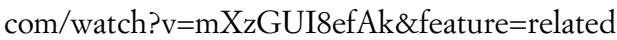

Mundo Livre S/A, Videoclipe da canção "Soy loco por sol” - http://www.youtube. $\mathrm{com} /$ watch?v=F7PQTFsmNCU\&feature=related 
Mundo Livre S/A, Videoclipe da canção “Azia amazónica” - http://www.youtube. com/watch?v=Kte4mWVrKHI

Nação Zumbi, Videoclipe da canção "Meu maracatu pesa uma tonelada" - http://www. youtube.com/watch?v=qFhkIy-Q3Jo\&feature=related

Nação Zumbi, Videoclipe da canção "Bossa nostra” - http://www.youtube.com/ watch?v=MN72ajWj_m4 